\title{
MISIÓN CENTRÍPETA Y MISIÓN CENTRÍFUGA DE LOS GRUPOS PEQUEÑOS
}

Bernui Contreras, Miguel

Facultad de Teología

Universidad Peruana Unión miguelbernui@teologia.edu.pe

Fecha de recepción: Julio 2012 Fecha de aceptación y versión final: Septiembre 2012

\section{Resumen}

A lo largo de la historia de la humanidad Dios siempre ha tenido un pueblo sobre quien ha depositado sus grandes verdades. Este pueblo siempre tuwo una misión que cumplir; es por causa de su dependencia a la voluntad divina y la obediencia a sus preceptos que muchas bendiciones les serían otorgadas. Entonces las naciones vecinas vendrian y preguntarian la razón de su prosperidad, esto es lo que llamamos misión centrípeta: la influencia sería de adentro hacia afuera. Con la llegada de Jesús el establece una misión mucho mas amplia, las personas no solo vendrían sino que su iglesia debería salir en busca de los perdidos; a esto llamamos misión centrifuga. En el presente artículo se describe de manera sucinta la labor de los grupos pequeños centrabdose en el, y el cumplimiento de esta doble misión. Una misión centrípeta que se evidencia en el cuidado y crecimiento de los miembros del grupo, una misión centrifuga: evidenciada en la urgencia con la que busca de las personas que sufren y necesitan del mensaje de salvación.

Palabras clave: Misión centrípeta, misión centrifuga, grupos pequeños. 


\section{Introducción}

El Señor ha contado desde el principio con aquellos hijos fieles que le servían y los ha hecho participes de su misión. Noé quien construyó el arca y se constituyó en instrumento de salvación para él y su familia es un ejemplo de esto. También Israel quien fue llamado a ser testimonio para todas las naciones y la iglesia de la época neotestamentaria en adelante que fue llamada a cumplir con la misión salvífica de ir en busca de los que han de formar parte de los redimidos tal como Jesús, pues "...el Hijo del hombre vino a buscar y salvar lo que se había perdido" (Lucas 19:10).

\section{Misión centrípeta del pueblo de Israel}

En el Antiguo Testamento Israel tiene una misión que cumplir en el propósito de Dios. Pero esta misión no consiste en la predicación a todo el mundo. En el Antiguo Testamento se evidencia y se entiende la misión de Israel de una manera "centrípeta" más bien que "centrífuga". Esto no significa que Israel vaya por todas las naciones del mundo predicando el mensaje de salvación, sino que todas las naciones del mundo encuentren en Israel su salvación. Esto a pesar de que las circunstancias fueran difíciles. Tal como lo podemos ver en la historia de Abraham en tierra extraña, José en Egipto y Daniel en la corte babilónica. Todos ellos cumplieron su cometido. El mundo vio en ellos la revelación de un Dios poderoso, percibió de manera real ya sea a través de manifestaciones portentosas o milagros evidentes el anhelo profundo de Dios de salvar a sus hijos.

El monte Sinaí se constituye en un hito importante en su experiencia. Este llamado del pueblo de Israel fue precisamente al pie del Sinaí donde Israel acampó al tercer mes después de salir de Egipto. También fue allí en donde Israel se rebeló contra Dios y adoró el becerro de oro, pero además fue el lugar en donde le dio la Ley a Moisés y llamó a Israel para que fuera instrumento salvífico a las otras naciones ${ }^{1}$ : "Ahora, pues, si diereis oído a mi voz, y guardareis mi pacto, vosotros seréis mi especial tesoro sobre todos los pueblos; porque mía es toda la tierra, y vosotros me seréis un reino de sacerdotes, y gente santa" ( Éxodo 19:3-6). Qué privilegio pero a la vez una

1 Larry D. Pate, Misionología: nuestro cometido transcultural (Florida: Editorial Vida, 1992), 13. 
gran responsabilidad ser considerado "especial tesoro" y "un reino de sacerdotes”. Había en el corazón y en la mente de cada israelita la clara concepción de la misión centrípeta. Mientras se mantuvieron fieles, la luz y la bendición divina los alcanzó y se convirtieron en fuente de salvación para otros pueblos; pero el día en que ellos rompían ese pacto mosaico la misión centrípeta se veía opacada. Esta misión "centrípeta" se manifiesta también en el ceremonial del templo.

"Mediante las enseñanzas del ceremonial del templo, Cristo había de ser exaltado ante todas las naciones, y cuantos la miraran vivirían. Cristo era el fundamento de la dispensación judía. Todo el sistema de los tipos y símbolos eran una profecía resumida del Evangelio, un medio a través del cual se presentaban las promesas de la redención”"

Que grandes y solemnes lecciones nos deja la historia del pueblo de Dios en el pasado, aprendamos juntos y por su gracia movilicémonos en el cumplimiento de la misión. Mientras nos mantengamos fieles al pacto

2 Elena G. de White, Los Hechos de los Apóstoles (Buenos Aires: Casa Editora Sudamericana, 1997), 13. hecho con Él, grandes serán sus bendiciones.

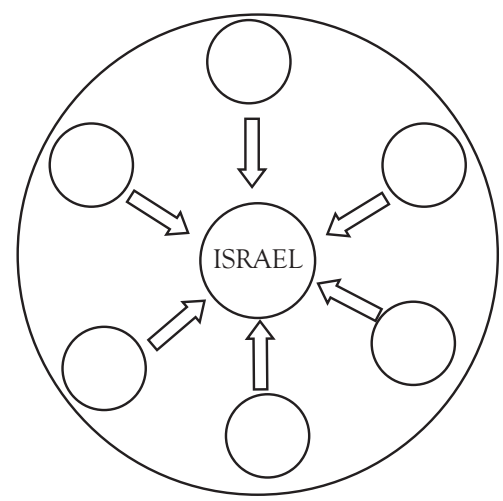

Ilustración 1: Misión centrípeta del pueblo de Israel: las naciones vendrían a él. Sería un "imán" salvífico para testificar de las bondades de Jehová.

\section{Misión centrífuga en la iglesia neotestamentaria}

Jesús es el misionero por excelencia y nuestro ejemplo a seguir. Inicia su ministerio, siendo consciente de la gran responsabilidad motivada por el amor a este mundo. En muchas oportunidades, se presenta como enviado, sobre todo en el evangelio de Juan: "el Padre que me ha enviado da testimonio de mí" (Jn 8,18); "vengo de Él y es Él quien me envió" (Jn 7,29).

Durante su vida terrenal, Je- 
sús tenía claramente su misión orientada primeramente al pueblo judío. Entonces cuando la mujer cananea le pide un milagro entonces le responde "Yo he sido enviado solamente a las ovejas perdidas del pueblo de Israel", (Mt 15,25). Pareciera que la dimensión universal de la misión están ausentes en la práctica y el ideal de Jesús. Sin embargo, a pesar de que Cristo presenta el mensaje de la salvación en primer lugar a su pueblo, la universalidad de su misión está claramente implícita en su obra. En este contexto durante los días previos a su ascensión, él proclama "“Pero recibiréis poder, cuando venga sobre vosotros el Espíritu Santo, y me seréis testigos en Jerusalén, en toda Judea, en Samaria, y hasta lo último de la tierra" (Hechos 1:8) entonces el evangelio ya no es más exclusividad ni privilegio de un pueblo sino que ahora la iglesia que Jesús deja establecida tiene un desafío: "anunciar entre los gentiles las inescrutables riquezas de Cristo" (Ef. 3,9).

Frente a la duda de algunos de sus discípulos de poder cumplir tan grande desafío Jesús les presenta la gran comisión registrada en Mateo 28:18-20. Esta ha sido, sigue y seguirá siendo la misma hasta que el vuelva por segunda vez. Es la columna vertebral de la iglesia que busca cumplir este gran cometido. En estos breves versículos se expresa de manera clara que el que envía tiene autoridad "potestad". Por lo tanto, su iglesia tiene que ir en "busca de los perdidos" no solo en función de esa autoridad sino porque él nos da esa autoridad y nos promete el poder del Espíritu Santo para realizar tan noble encargo.

En la expresión "hagan discípulos a todas las naciones" se describe claramente la misión centrifuga de la iglesia neotestamentaria: la universalidad de la predicación a todas las naciones y pueblos. Esta iglesia ya no espera que los demás vengan y pregunten, sino que goza de tantas bendiciones a pesar de las dificultades y vicisitudes que sus miembros enfrentan. Y sin embargo, se mantienen incólumes, mostrando gozo, alegría, serenidad y paz en medio de las más inesperadas tribulaciones. Ésta es una iglesia que va en busca de los familiares, vecinos, amigos y la comunidad para mostrarles la razón de su esperanza independientemente de su cultura, nacionalidad o posición social. 
Éste es nuestro gran desafío en este tiempo:

La comisión evangélica elimina las fronteras nacionales, y los habitantes de todas las naciones se convierten en miembros de una gran hermandad en la cual "no hay judío ni griego; no hay esclavo ni libre; no hay varón ni mujer; porque todos" somos "uno en Cristo Jesús"3 (Gl 3: 28; Cl. 3:11).

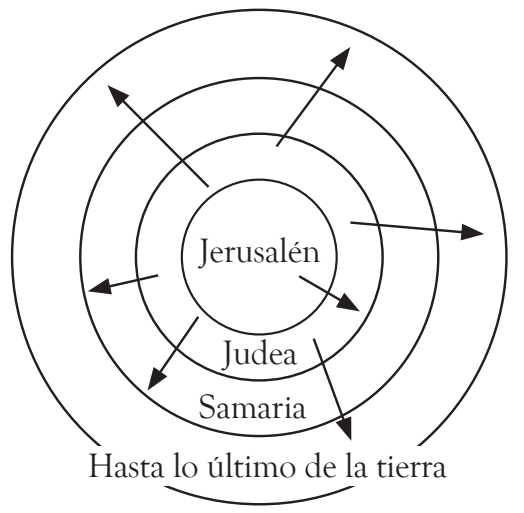

Ilustración 2: Misión centrifuga de la iglesia neo testamentaria, el cumplimiento de la misión: "todas las naciones, tribus, lenguas y pueblos"

3 Francis D. Nichol, ed. Comentario Bíblico Adventista del Séptimo Día, Trad. Víctor E. Ampuero Matta (Buenos Aires: Asociacion Casa Editora Sudamericana, 1992), 5:545.

\section{Misión centrípeta y centri- fuga de los grupos pequeños}

El pueblo de Israel tenía su misión claramente establecida. Era una misión centrípeta. Tenían que ser "luz para las naciones". Los pueblos vecinos de cerca y de lejos vendrían a preguntar la razón de su prosperidad y éste era el momento cuando ellos testificaban que la razón de su éxito era su dependencia plena de Jehová.

En la iglesia neotestamentaria la misión se amplia, Jesús da ejemplos claros de la misión centrifuga de su iglesia cuando va en busca de la samaritana. La Escritura dice: "le era necesario pasar por Samaria”. Jesús no esperó que ella fuese, pues con toda seguridad ella nunca hubiese experimentado el perdón y la satisfacción de una vida plena si Jesús no hubiese ido en busca de ella. Aquí tenemos la misión centrífuga evidenciada y ejemplificada por el gran Maestro.

En este contexto la iglesia del tiempo del fin, una iglesia profética, ahora tiene un gran desafío. Este desafío consiste en el de ser una iglesia dinámica con un crecimiento explosivo, una iglesia que tiene un mensaje ur- 
gente que proclamar a un mundo que perece en el dolor y la desesperanza, una iglesia cuyos miembros perciben el suave susurro del Espíritu Santo diciendo: ¿quien irá por nosotros?, una iglesia que responde tal como el profeta Isaías: "heme aquí, envíame a mi”. Esta iglesia comprende que:

La formación de pequeños grupo como base del esfuerzo cristiano me ha sido presentada por Uno que no puede errar ${ }^{4}$.

Es justamente a través de los grupos pequeños como esta doble misión centrípeta y centrifuga se pueden cumplir. La misión centrípeta de los grupos pequeños se cumple cuando los invitados van a las reuniones establecidas en las casas, preguntando cual es la razón de la prosperidad y esperanza que ustedes transmiten aun en medio de las perplejidades. Y la misión centrifuga se realiza cuando los miembros de los grupos pequeños se organizan en parejas misioneras celosas y fervientemente misioneras llevan el mensaje de salvación a los familiares, amigos y vecinos de la comunidad. Todo esto, para dar esperanza al deses-

4 Elena G. de White, Joyas de los Testimonios (Buenos Aires: Casa Editora Sudamericana, 1977), 3:84 peranzado y el "Agua de Vida" al sediento que perece en el desierto de esta vida.

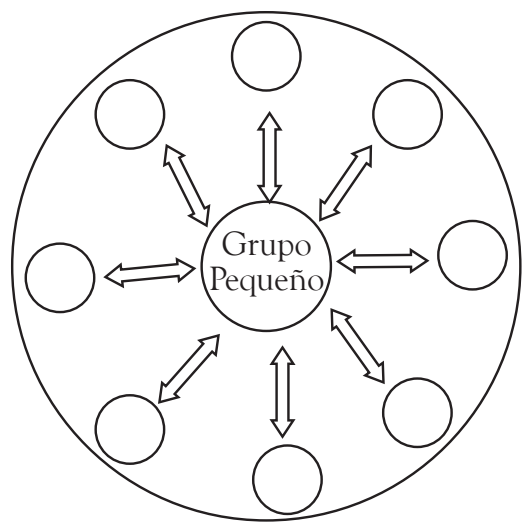

Ilustración 3: La misión centrípeta y centrifuga de los grupos pequeños, doble función en el cumplimiento de la misión.

El apóstol Pablo sentía que era responsable del bienestar espiritual de aquellos que se convertían producto de sus esfuerzos y la obra maravillosa del Espíritu Santo. Él anhelaba que crecieran en el conocimiento del único Dios verdadero y de Jesucristo:

A menudo en su ministerio se encontraba con pequeños grupos de hombres y mujeres que amaban a Jesús, y se postraba en oración con ellos para pedir a Dios que les enseñara cómo mantener una relación vital con 
él. A menudo se reunía en consejo con ellos para estudiar los mejores métodos de dar a otros la luz de la verdad evangélica. ${ }^{5}$

Es esta la noble tarea que corresponde realizar a nuestra iglesia en este tiempo. La misión centrípeta ayudará a fortalecer el grupo pequeño, le da estabilidad, momentos de compañerismo y confraternidad e inclusión de los nuevos miembros; pero una misión centrifuga lleva a los integrantes del grupo pequeño a proclamar la "Bienaventurada esperanza”.

Los grupos pequeños deben ir a cumplir la obra que Cristo asignó a sus discípulos. Trabajen como evangelistas, repartiendo nuestros impresos, hablando de la verdad a las personas que encuentren ${ }^{6}$.

\section{A manera de testimonio}

He tenido el privilegio de trabajar como pastor distrital durante 10 años en diferentes misiones, rodeado de diferentes iglesias y líderes extraordinarios que han tenido clara cuál es la misión que tiene esta maravillo-

5 Elena G. de White, Los hechos de los apóstoles, 212.

6 Elena G. de White, Joyas de los testimonios, 3:371. sa iglesia. Los grupos pequeños que se comprometieron, que organizamos y que fueron conscientes de la misión, centrípeta y centrífuga, siempre vieron cómo Dios obró poderosamente a través de ellos durante las reuniones evangelísticas. Éstos, con satisfacción y alegría fueron testigos de cómo las personas por quienes trabajaron entregaban sus vidas al Señor y lo evidenciaban a través del santo bautismo.

Talvez pensemos que los grupos pequeños solo funcionan en algunos lugares y en otros no. Tuve el privilegio de estar en diferentes latitudes y puedo dar testimonio que los grupos pequeños son el plan de Dios para la iglesia en este tiempo. Por ejemplo, durante el año 2005 fui invitado a predicar en la iglesia de Hattiesburg, Mississippi. El pastor Nilton García había organizado a su iglesia en grupos pequeños desde comienzos del año y los había desafiado al cumplimiento de la misión. Cuando llegamos para la campaña los grupos pequeños traían a sus invitados y la pequeña iglesia tenía cada noche 30 personas aproximadamente. Los grupos de oración estaban activos, el plan de visitación se rea- 
lizaba en horarios establecidos; la programación de cada noche era inspiradora. Así, al finalizar la semana 18 personas fueron bautizados de los 30 invitados que asistieron. Éste es un número de bautismos poco común en Norteamérica y sobre todo en una iglesia pequeña con una infraestructura sencilla. ¿A qué atribuimos el éxito de esta campaña? Primero e indudablemente a la obra del Espíritu Santo, pero no hubieran sido posibles los resultados obtenidos, sin el compromiso y el trabajo de los grupos pequeños que cumplieron la doble misión: centrípeta y centrifuga. No solo invitaban sus familiares y amigos a las reuniones, sino que iban a sus hogares, oraban con ellos, satisfacían sus necesidades, se preocupaban por las luchas que enfrentaban al intentar seguir a Jesús. Finalmente estaban listos para unirse a la iglesia. La campaña solo fue el toque que necesitaban para dar testimonio público de su fe. La inversión fue mínima y el resultado maravilloso.

El año 2008 tuve el privilegio de visitar la ciudad de Bogotá y dirigir una campaña en la iglesia de Luna Park. Ésta era una hermosa iglesia con los mismos desafíos que la iglesia de Hatties- burg o su iglesia en la que usted y yo congregamos. El pastor tenía organizada su iglesia en grupos pequeños. Pero, a diferencia de la primera iglesia en donde todos los grupos pequeños estaban activos, la iglesia de Luna Park tenía solo 3 grupos. Éstos estaban comprometidos en el cumplimiento de la misión. Al final de la campaña, 15 personas fueron bautizadas y nos alegramos por este número. Sin embargo, más personas pudieron entregarle la vida a Cristo, si es que los miembros de los otros grupos pequeños hubieran estado involucrados tanto con la misión centrípeta - compañerismo, conservación, oración- y con la misión centrifuga. Esta misión incluía ir en busca de los perdidos, orar con ellos en sus hogares, traerlos a las reuniones, satisfacer sus necesidades físicas, espirituales y emocionales. Éste es un desafío para todos nuestros grupos pequeños.

\section{Conclusión}

Recuerde que nuestra iglesia tiene una misión que cumplir, los grupos pequeños no deben de ser una estrategia misionera de la iglesia, sino el estilo de vida de la misma. Entonces, cuando los miembros que están involu- 
crados en los grupos pequeños son conscientes de la comisión dada por el gran Maestro asistirán a las reuniones programadas por el grupo. Los lazos de amistad se fortalecerán, demostrarán afecto y sinceridad el uno para con el otro, se edificarán y crecerán espiritualmente de manera recíproca. Todo esto es la misión centripeta. Pero, asimismo, la misión centrifuga será inevitable; serán sensibles al sufrimiento de las personas. Organizarán parejas misioneras, saldrán a proclamar las "Buenas Nuevas" a sus familiares, amigos y vecinos, visitaran los hogares, orarán por las familias, sus pies irán presurosos a visitar a los enfermos y encarcelados y con toda seguridad la promesa hecha por el Maestro de Galilea se cumplirá. Tal como la Escritura dice: "Irá andando y llorando el que lleva la preciosa semilla; mas volverá a venir con regocijo, trayendo sus gavillas". (Sal 126: 6). Por lo tanto, involúcrese, forme parte de un grupo pequeño y disfrute de la misión centrípeta y centrífuga que éste experimenta. 